\title{
R\&D Investment Competition and Efficiency in a Mixed Duopoly Model, with Endogenous Spillover
}

\author{
Jie Han ${ }^{1, a *}$, Zelong $\mathrm{Li}^{2}$ \\ ${ }^{1}$ Dept. of Economics, North China University of Technology, Beijing, China \\ ${ }^{2}$ Dept. of Economics, North China University of Technology, Beijing, China
}

\begin{abstract}
In this paper, a mixed duopoly model is used to explain how ownership structure influences the innovation performances of firms. A three stage-game is adopted in the study. In first stage, firms make R\&D expenditure which leads to a profit increasing; in the second stage, firms choose the level of technological improvement they would like to share with the rival; and production quantity will be decided in the final stage. The theory explains that as long as public firms continue their dual roles as productive entities and social safety nets, they cannot be purely profit-oriented, and continue to have poor innovation performance.
\end{abstract}

\section{INTRODUCTION}

Mixed duopoly model is a model in which there are one private-sector profit-maximising firm and one public firm pursuing a non-profit objective of social welfare. The mixed market theory is largely consistent with the current ownership structure in many of economies, especially in transitioning economy.

This research focuses on the situation where there is imperfect appropriability of knowledge. This is captured through the existence of R\&D spillover. Most technologies have some public good aspects. Whether $R \& D$ findings are perfectly appropriable by the inventing firm or not is an important issue concerned by researchers. $R \& D$ spillover has emerged as one of the most active issue that might influence the firms R\&D investment decision.

In reality, however, there might be various settings in which firms will generate more than they receive or vice versa. The contribution we have made is to endogenise the extent of protection of intellectual property that the two types of firms would seek. That is we endogenise the level of spillover - subject to there being an irreducible minimum level of spillover that any firm can obtain.

In this paper, we adopt a three stage-game. In first stage, firms make $R \& D$ expenditure which leads to a profit increasing (cost reducing \& quality improving); in the second stage, firms choose the level of technological improvement they would like to share with the rival; and production quantity will be decided in the final stage.

The key result is that while a welfare-maximising public firm will recognize and value the positive externality flowing from its $R \& D$ and so choose a minimum level of intellectual protection - maximum spillover. Because of its social welfare maximum aim, the public firm will see a higher benefit for the society as whole of its $R \& D$ than the private firm whose aim is just its own profit and public firm will do more R\&D.

This paper is organized as follows: Section 2, Literature review; Section 3, Set a R\&D model of mixed duopoly; Section 4, Present the equilibrium R\&D spillover rate, R\&D efficiency and R\&D investment amount; and Section 5, Concludes the paper.

\section{LITERATURE REVIEW AND INSTITUTIONAL BACKGROUND}

\section{A. Literature Review}

Mixed market theory, characterized by the presence of both profit maximizing private firms and welfare maximizing public sector firms has been widely applied to the research of innovation ( De Fraja and Delbono, 1990)[1].

Some of them assume that firms can engage in cost reducing process innovations in order to lower their marginal costs and there are diminishing returns to the level of R\&D expenditure (Zikos, 2007)[2]. Some of them assume that the marginal cost is constant and independent of the quality and can make demand-enhancing investment into quality. (Ishibashi and Kaneko, 2008)[3].

Under easy imitation assumption, Poyago-Theotoky (1998) shows there is under investment problem because firm might well leave R\&D to its rivals to carry out and then reap benefits through easy imitation[4]. Gil-Moltó et al. (2011) assume that the degree of spillovers among the duopolists is exogenously given and concludes that the

${ }^{* a}$ Corresponding author E-mail address: grace.han@qq.com 
$\mathrm{R} \& \mathrm{D}$ of the private firm may increase or decrease, depending on the rate of spillover. The optimal subsidy is always positive and increasing in the rate of spillover[5].

Given the asymmetric objectives of the firms, Naseem and Oehmke (2006) assume that spillover from the public firm will be greater than from the private firm[6]. This is consistent with the observation that public sector firms are more open to disseminating their research results to private. However, they did not investigate how this asymmetric spillover influences the public and private firms' different R\&D investment volume and efficiency. For both the public and private firms, research effort is decreasing in input spillover from the rival, but is ambiguous for their own input spillover.

Heywood and Ye (2009) prove in duopoly model that the public firm invests more in R\&D than its private rival[7]. Gil-Moltó et al. (2011) finds support for the empirical claim that privatization is followed by a scaling down of the R\&D activity. Other things being equal, total $R \& D$ investment and output are always higher in the mixed duopoly than in the private duopoly.

\section{B. Institutional Background}

It is well known that R\&D has become increasingly important not only for individual firm's survival and growth, but also the development of the whole economy. Ownership structure and its concentration have important role in the firm's strategy of R\&D investment. With China still being in transition from its central planning legacy, ownership might be anticipated to play an active role in financing and directing firms' R\&D activities. The ownership structure has become more diversified since China started its economic reform from 1979.

Spectacular expansion of non-state sector innovation activities had attracted the notice of policy makers and economists. The data derived from the Statistics on Science and Technology for Industrial Enterprises 20042017, which record R\&D data for large and medium size industrial enterprises, shows that new products development expenditure of the private sector grows much faster than that of the state owned sector as shown in figure 1 .

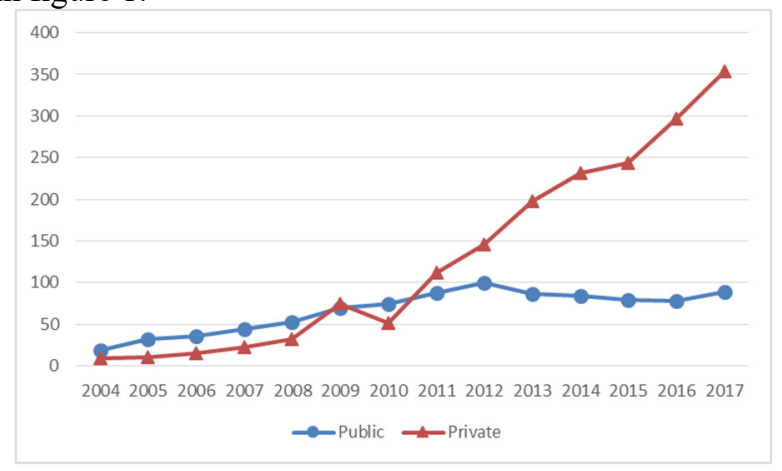

Figure 1. New Products Development Expenditure

Private sector provides most of the new products sales growth as show in figure 2 .

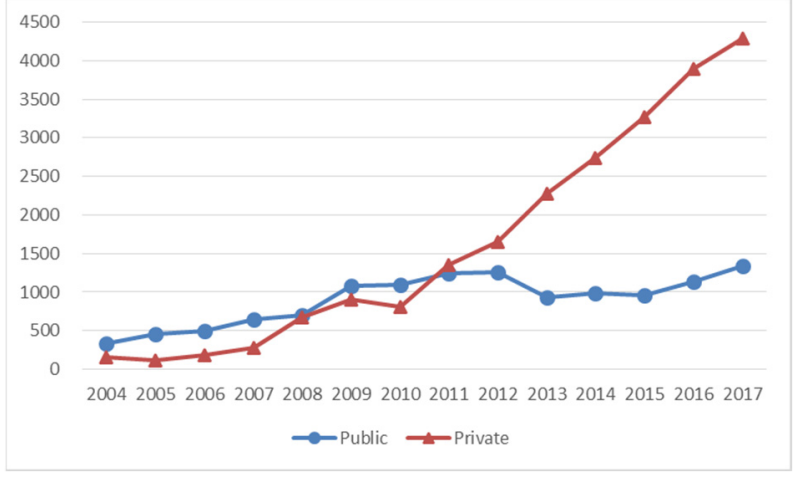

Figure 2. Sales Revenue of New Products

\section{MODEL}

There are two firms A and B that produce homogenous products in the market. A is a public firm and B is a private firm. They play a 3 stage game to decide their optimal $R \& D$ level and spillover rate. In the first stage, firms make $R \& D$ expenditure which leads to profit increasing (cost reducing \& quality improving). In the second stage, firms choose the level of technology improvement they would like to share with the rival. Production quantity will be decided in the final stage.

\section{A. Stage I R\&D Activities}

Assumption 1 If let $x_{A}$ (resp. $x_{B}$ ) denote the $R \& D$ input undertaken by the public ( resp. private) firm. $R \& D$ generates discoveries via the $R \& D$ production function: $I_{A}=f\left(x_{A}\right),\left(\right.$ resp. $\left.I_{B}=f\left(x_{B}\right)\right)$,

Where $f$ satisfies all the usual assumptions: $f(0)=0$, $f^{\prime}(x)>0, f^{\prime \prime}(x)<0$.

\section{B. Stage II Spillover}

Assumption 2 The link between discoveries and total progress depends on spillover which reflects the degree to which each firm can protect its ideas. So let $\beta, 0<\beta \leq$ $\beta_{A} \leq 1 ;\left(0<\underline{\beta} \leq \beta_{B} \leq 1\right)$ be spillover rate from public firm to private firm (resp. from private firm to public firm), where $\underline{\beta}, 0<\underline{\beta}<1$ is minimum unavoidable spillover. Then we have total progress made by firms $t$ :

$$
t_{A}=I_{A}+\beta_{B} I_{B} ; t_{B}=I_{B}+\beta_{A} I_{A}
$$

$I_{i}$,represents R\&D discoveries generated via the R\&D production function:

The link between discoveries and total progress depends on spillover which reflects the degree to which each firm can protect its ideas. Each firm's final technology progress is the sum of its own discoveries and a fraction (equal to the spillover parameter) of the other firms' part.

\section{Stage III Product Market}

Rather than developing a formal model of product market competition, we will use a reduced form approach in 
which we represent the object of the two firms' profit and social welfare as function of the outcome of previous studies of the game.

\section{Assumption about firms' profit}

Let $t_{j}, j=A, B$ be the total progress made by firm $\mathrm{j}$ in reducing its costs and/or improving its product quality as a result of the $R \& D$ it has done in Stage 1 and any knowledge spillover it has acquired from the other firm in Stage 2.

Let $\pi_{j}\left(t_{A}, t_{B}\right)$ be the operating profit of firm $\mathrm{j}$ as a result of the progress made by each of the two firms. We make the natural assumption that

(i) eash firm's profit is an increasing function of the progress that it has made and decreasing function of the progress made by its rival;

(ii) the impact on profit of a firm's own progress dominates the impact of its rival's progress.

So formally we assume:

\section{Assumption 3}

$$
\frac{\partial \pi_{i}}{\partial \pi_{j}}>0 ; \frac{\partial \pi_{j}}{\partial t_{k}}<0 ; j, k=A, B ; j \neq k
$$

So each firm's profit is increasing in own $R \& D$ progress and decreasing in rival's progress.

Assumptions about the consumer surplus and social welfare

The objective function of the public firm is social welfare which is consumer surplus plus producer surplus, where the latter is the total operating profits of the two firms.

Formally,

$$
S\left(t_{A}, t_{B}\right)=\pi_{A}\left(t_{A}, t_{B}\right)+\pi_{B}\left(t_{A}, t_{B}\right)+C S\left(t_{A}, t_{B}\right)
$$

Where $S\left(t_{A}, t_{B}\right)$ denotes social welfare and $\operatorname{CS}\left(t_{A}, t_{B}\right)$ is consumer surplus.

It is natural to assume that greater is the technological progress that each firm makes in lowering its costs and/or improving the quality of its product, the greater is the consumer surplus.

So formally we make the following assumption:

\section{Assumption 4}

$$
\frac{\partial C S}{\partial t_{A}}>0 ; \frac{\partial C S}{\partial t_{B}}>0
$$

For the main result of this paper, we will make the following assumption:

\section{Assumption 5}

$$
\begin{gathered}
\text { (i) } \frac{\partial S}{\partial t_{B}}>\frac{\partial \pi_{B}}{\partial t_{B}}>0 ; \\
\text { (ii) } \frac{\partial S}{\partial t_{A}}+\frac{\partial S}{\partial t_{B}}>\frac{\partial \pi_{A}}{\partial t_{A}}+\frac{\partial \pi_{B}}{\partial t_{B}}>0
\end{gathered}
$$

Though strictly speaking assumption 5(ii) is stronger than we need.

Welfare conclusion is difficult to draw. A profit increase in the R\&D winner firm will lead to the profit decrease in another firm. But it is reasonable to assume that former is higher than the latter. Plus there is increase in consumer surplus, so social welfare will increase with any firm's technology improvement.

\section{EQUILIBRIUM}

In this section, we will solve the equilibrium spillover rate and R\&D efficiency in second stage and R\&D investment level in the first stage.

\section{A. R\&D Spillover}

We have already assumed that there are two firms compete in the product market. One is public firm and another is private firm. Private firm is assumed to be profit-maximizer while public firm is assumed to maximize social welfare.

Consider following game in which the public firm takes $x_{A}, x_{B}, \beta_{B}$ as given and choose $\beta_{A}$ to

$$
\begin{gathered}
\underset{\beta_{A}}{\operatorname{Max}} S\left[f\left(x_{A}\right)+\beta_{B} f\left(x_{B}\right) ; f\left(x_{B}\right)+\beta_{A} f\left(x_{A}\right)\right]-x_{B}-x_{A} \\
\text { While private firm takes } x_{B}, x_{A}, \beta_{A} \text { as given and }
\end{gathered}
$$
chooses $\beta_{B}$ to

$$
\operatorname{Max}_{\beta_{B}}\left\{\pi_{B}\left[f\left(x_{A}\right)+\beta_{B} f\left(x_{B}\right) ; f\left(x_{B}\right)+\beta_{A} f\left(x_{A}\right)\right]-x_{B}\right\}
$$

Proposition 1 There is full spillover from public firm to private firm, while only miminum spillover from private firm to public firm. Because of spillover effect, $t_{A} \leq t_{B}$; public firm always achieves less progress than private firm, which indicates that private firm is more efficient in $R \& D$ than public firm.

$$
\beta_{A}=1, \beta_{B}=\underline{\beta} ; t_{A} \leq t_{B}
$$

Proof From assumption 5, we can get $\frac{\partial S}{\partial t_{B}}>0, t_{B}=$ $f\left(x_{B}\right)+\beta_{A} f\left(x_{A}\right)$, and $f\left(x_{A}\right)>0$ so $\mathrm{S}$ will increase with $\beta_{A}$, and because $0<\beta_{A} \leq 1$, so the optimal $\beta_{A}$ equals 1 . There is full spillover from public firm to private firm is proved.

From assumption 3, we get $\frac{\partial \pi_{B}}{\partial t_{A}}<0, \quad t_{A}=f\left(x_{A}\right)+$ $\beta_{B} f\left(x_{B}\right)$, and $f\left(x_{B}\right)>0$, so there is negative relationship between $\pi_{B}$ and $\beta_{B}$, and also $0<\beta \leq \beta_{B} \leq$ 1 , private firm will choose minimum spillover rate which equals $\underline{\beta}$.

Substitute $\beta_{A}=1, \beta_{B}=\beta$ into $t_{A}=f\left(x_{A}\right)+$ $\beta_{B} f\left(x_{B}\right)$ and $t_{B}=f\left(x_{B}\right)+\bar{\beta}_{A} f\left(x_{A}\right)$, we can gett $t_{A}=$ $f\left(x_{A}\right)+\underline{\beta} f\left(x_{B}\right)$ and $t_{B}=f\left(x_{B}\right)+f\left(x_{A}\right)$, because $\beta \leq 1, \mathrm{t}_{A} \leq t_{B}$ is proved. Public firm always achieves less progress than private firm, which indicates that private firm is more efficient in $R \& D$ than public firm.

\section{B. R\&D Invest Amount}

Proposition $2 \boldsymbol{x}_{\boldsymbol{A}}>\boldsymbol{x}_{\boldsymbol{B}}$ that R\&D investment amount of public firm is higher than it of private firm.

Proof We substitute the optional spillover rate into the optimization functions

$$
\beta_{A}=1, \beta_{B}=\underline{\beta}
$$

Public firm takes $x_{B}$ as given and chooses $x_{A}$ to 


$$
\begin{gathered}
\underset{x_{A}}{\operatorname{Max}}\left\{S\left[f\left(x_{A}\right)+\beta f\left(x_{B}\right) ; f\left(x_{B}\right)+f\left(x_{A}\right)\right]-x_{B}-\right. \\
\left.x_{A}\right\} \quad \text { While private firm takes } x_{A} \text { as given and chooses }
\end{gathered}
$$
$x_{B}$ to

$$
\operatorname{Max}_{x_{B}}\left\{\pi_{B}\left[f\left(x_{B}\right)+f\left(x_{A}\right) ; f\left(x_{A}\right)+\underline{\beta} f\left(x_{B}\right)\right]-x_{B}\right\}
$$

Optimization function can be reorganized as

Public firm:

Private firm:

$$
f^{\prime}\left(x_{A}\right)\left[\frac{\partial S}{\partial t_{A}}+\frac{\partial S}{\partial t_{B}}\right]=1
$$

$$
f^{\prime}\left(x_{B}\right)\left[\frac{\partial \pi_{B}}{\partial t_{B}}+\underline{\beta} \frac{\partial \pi_{B}}{\partial t_{A}}\right]=1
$$

From assumption 1, we have known that $f^{\prime}(x)>$ $0, f^{\prime \prime}(x)<0$. Because $f^{\prime \prime}(x)<0$, $f^{\prime}\left(x_{A}\right)<f^{\prime}\left(x_{B}\right)$, so $\frac{\partial S}{\partial t_{A}}+\frac{\partial S}{\partial t_{B}}>\frac{\partial \pi_{B}}{\partial t_{B}}+\underline{\beta} \frac{\partial \pi_{B}}{\partial t_{A}}$.

Similar analysis for $x_{A} \leq x_{B}$,

So it is clear that:

$$
x_{A} \frac{>}{<} x_{B} \Leftrightarrow \frac{\partial S}{\partial t_{A}}+\frac{\partial S}{\partial t_{B}} \geq \frac{\partial \pi_{B}}{\partial t_{B}}+\underline{\beta} \frac{\partial \pi_{B}}{\partial t_{A}}
$$

Now we have

$$
\begin{gathered}
\frac{\partial S}{\partial t_{A}}+\frac{\partial S}{\partial t_{B}}=\left[\frac{\partial \pi_{B}}{\partial t_{B}}+\beta \frac{\partial \pi_{B}}{\partial t_{A}}\right]+\left[\frac{\partial S}{\partial t_{A}}-\underline{\beta} \frac{\partial \pi_{B}}{\partial t_{A}}\right] \\
+\left[\frac{\partial S}{\partial t_{B}}-\frac{\partial \pi_{B}}{\partial t_{B}}\right]
\end{gathered}
$$

From assumption 3 and 4 , we know, that $\frac{\partial \pi_{B}}{\partial t_{A}}<$ 0, so $-\underline{\beta} \frac{\partial \pi_{B}}{\partial t_{A}}>0$ and $\frac{\partial S}{\partial t_{A}}>0$, so $\left[\frac{\partial S}{\partial t_{A}}-\underline{\beta} \frac{\partial \pi_{B}}{\partial t_{A}}\right]>0$

From assumption 5, we know that $\left[\frac{\partial S}{\partial t_{B}}-\underline{\beta} \frac{\partial \pi_{B}}{\partial t_{B}}\right]>0$

So $\left[\frac{\partial S}{\partial t_{A}}+\frac{\partial S}{\partial t_{B}}\right]>\frac{\partial \pi_{B}}{\partial t_{B}}+\underline{\beta} \frac{\partial \pi_{B}}{\partial t_{A}} \Leftrightarrow x_{A}>x_{B}$, that R\&D investment amount of public firm is higher than private firm.

\section{CONCLUSION}

The aim of this paper has been to provide a theoretical framework to explain how ownership structure influences the innovation performances of firms. To explore this issue, we have used a mixed duopoly model that is a model in which there is one private-sector profitmaximising firm and one public firm pursuing a nonprofit objective of social welfare. Both firms undertake
$\mathrm{R} \& \mathrm{D}$ which, in this model, is process (cost-reducing or quality improving) R\&D.

The contribution we have made is to endogenise the extent of protection of intellectual property that the two types of firms would seek.

This has two further implications:

(1) Because of its higher spillover the public firm will see a higher social return to its R\&D than the private firm and so do more of it.

(2) Because the private firm benefits from the higher spillover of the public firm while the public firm gets a minimum spillover from the lower level of R\&D by the private firm, the total amount of progress made by the public firm relative to its $R \& D$ is lower than the total amount of progress made by the private firm in relation to its R\&D.

\section{Acknowledgment}

This work was supported by North China University of Technology under Grant No.110051360002 and Beijing Municipal Education Committee under Grant No. SM202010009009.

\section{REFERENCES}

1. De Fraja G., Delbono F., 1990. Game Theoretic Models of Mixed Oligopoly. Journal of Economic Surveys, Vol.4(1), pp.1-17.

2. Zikos V., 2007. A Reappraisal of the Irrelevance Result in Mixed Duopoly: A Note on R\&D Competition. Economics Bulletin, Vol.12(8), pp.1-6.

3. Ishibashi K., Kaneko T., 2008. Partial Privatization in Mixed Duopoly With Price and Quality Competition. Journal of Economics, Vol.95, pp.213-231.

4. Poyago-Theotoky J., 1998. R\&D Competition in a Mixed Duopoly under Uncertainty and Easy Imitation, Journal of Comparative Economics, Vol.26, pp.415-428.

5. Gil-Moltó M.J., Poyago-Theotoky J. and Zikos V., 2011. R\&D Subsidies, Spillovers and Privatization in Mixed Markets, 2011, Southern Economic Journal, 78(1), pp.233-255.

6. Naseem A., Oehmke J. F., 2006. Spillovers, Joint Ventures and Social Welfare in a Mixed Duopoly R\&D Race. Selected Paper Prepared for Presentation at the American Agriculture Economics Association Annual Meeting, Long Beach, CA, pp.1-26.

7. Heywood J. S., Ye G., 2009. Partial Privatization in a Mixed Duopoly with an R\&D Rivalry. Bulletin of Economic Research, Vol.61(2), pp.165-178. 